\title{
Темплатный синтез монодисперсных сферических нанопористых частиц кремния субмикронного размера
}

\author{
(ㄱ Д.А. Курдюков, Н.А. Феоктистов, Д.А. Кириленко, А.Н. Смирнов, В.Ю. Давыдов, В.Г. Голубев \\ Физико-технический институт им. А.Ф. Иоффре, \\ 194021 Санкт-Петербург, Россия \\ E-mail: kurd@gvg.ioffe.ru
}

Поступила в Редакцию 26 марта 2019 г.

В окончательной редакции 1 апреля 2019 г.

Принята к публикации 1 апреля 2019 г.

\begin{abstract}
Получены субмикронные монодисперсные сферические нанопористые частицы кремния с использованием мезопористых частиц кремнезема в качестве темплата. Кремний синтезирован в порах монодисперсных частиц кремнезема путем термического разложения моносилана, затем темплат $\left(a-\mathrm{SiO}_{2}\right)$ удален методом жидкостного химического травления. Частицы имеют низкое среднеквадратичное отклонение размеров (не более $10 \%$ ), обладают большими удельной поверхностью $\left(250 \mathrm{~m}^{2} / \Gamma\right)$ и объемом пор $\left(0.5 \mathrm{~cm}^{3} / \Gamma\right)$. Продемонстрировано, что полученные частицы люминесцируют в видимом и ближнем ИК спектральных диапазонах.
\end{abstract}

Ключевые слова: темплатный синтез, кремний, силан, монодисперсные мезопористые частицы.

DOI: 10.21883/FTP.2019.08.47997.9116

\section{1. Введение}

Биосовместимость, низкая токсичность и способность к биоразложению пористого кремния [1-4], а также наличие люминесцентных свойств [5-8] обусловливают работы по созданию на его основе многофункциональных наночастиц для диагностики и терапии различных заболеваний [3,9-13]. Распространенными подходами к получению пористого кремния $(p-\mathrm{Si})$ является жидкостное или газофазное травление монокристаллического $\mathrm{Si}$, зачастую с приложением внешних воздействий (электрического поля, лазерного излучения, обработки плазмой) [5,9,10]. Для формирования наноразмерных частиц полученная в результате травления пленка $p-\mathrm{Si}$ подвергается механическому или ультразвуковому диспергированию. На заключительном этапе для сепарации по размерам наночастицы $p$-Si подвергаются центрифугированию и фильтрации.

Получаемые наночастицы $p$-Si, как правило, значительно отличаются по форме и размерам, тогда как для большинства медицинских применений востребованы частицы одинакового калиброванного размера [14]. Монодисперсность наночастиц обусловливает идентичность их гидродинамических свойств, а одинаковость формы частиц определяет одинаковую скорость их проникновения через клеточную мембрану [15]. Зачастую частицы $p$-Si имеют острые поверхности, что затрудняет их применение в медицине, поскольку частицы с острыми гранями являются более цитотоксичными, чем сферические [16].

Монодисперсные частицы могут быть получены темплатным методом. Среди темплатов отметим мезопористые частицы кремнезема (МЧК), обладающие большими удельной поверхностью и объемом пор $[17,18]$. Традиционно, для синтеза целевых веществ в мезопорах используют жидкостной метод, а именно заполнение пор темплата раствором или расплавом прекурсора с его последующим разложением и синтезом в порах целевого вещества. Ранее таким способом нами были синтезированы металлы [19], оксиды [20,21], нитриды [22], углеродные наноточки [23,24]. В качестве темплата использовали монодисперсные сферические мезопористые частицы кремнезема (МСМЧК) [25,26]. Благодаря строго одинаковым форме и размеру МСМЧК (среднеквадратичное отклонение диаметров менее 10\%) при синтезе целевого вещества достигается идентичность условий протекания реакций внутри каждой частицы, а монодисперсные мезопоры обусловливают одинаковый размер формирующихся в них материалов.

В настоящей работе темплатным методом получены монодисперсные сферические нанопористые частицы кремния ( $n p-\mathrm{Si})$ субмикронного размера. Для получения целевого вещества в порах МСМЧК применен газофазный прекурсор. Кремний синтезирован в порах МСМЧК термическим разложением моносилана $\left(\mathrm{SiH}_{4}\right)$, затем $\mathrm{SiO}_{2}$ удален с помощью травления водным раствором HF. Проведена характеризация синтезированных частиц $n p-\mathrm{Si}$ методами просвечивающей электронной микроскопии, динамического светорассеяния, спектроскопии фотолюминесценции и рамановского рассеяния. Продемонстрировано, что после вытравливания материала темплата частицы $n p$-Si сохраняют сферическую форму и не распадаются с образованием мелких фрагментов. Частицы $n p$-Si имеют размер, равный размеру исходных МСМЧК, и среднеквадратичное отклонение диаметров менее $10 \%$. Показано, что частицы $n p-\mathrm{Si}$ люминесцируют в видимой и ближней инфракрасной (ИК) областях спектра. 


\section{2. Методика эксперимента}

Монодисперсные сферические мезопористые частицы кремнезема диаметром 420 нм синтезированы путем гидролиза тетраэтоксисилана в этаноло-водно-аммиачной среде при температуре $55^{\circ} \mathrm{C}$ в присутствии структурообразующего вещества цетилтриметиламмоний бромида в мольном соотношении реагентов $1: 60: 370: 230: 0.2$ соответственно. Для удаления органических веществ синтезированные частицы были отожжены на воздухе при температуре $550^{\circ} \mathrm{C}$. Среднеквадратичное отклонение диаметров частиц составило менее $6 \%$, диаметр мезопор $3.1 \pm 0.15$ нм, объемная доля пор $\sim 50 \%$ об. от объема частиц, удельная поверхность $750 \mathrm{~m}^{2} /$ г. Метод синтеза частиц $\mathrm{SiO}_{2}$ позволяет управлять внешним диаметром и пористой структурой МСМЧК. Подробно методика синтеза частиц описана в работах $[17,25,26]$.

Для введения кремния в поры МСМЧК использовался модифицированный метод термического разложения моносилана, ранее разработанный нами для введения кремния в макропоры искусственных опалов $[27,28]$. Газовая смесь $\mathrm{SiH}_{4}(5 \%)$ с $\mathrm{Ar}$ (объемный расход смеси $1 \mathrm{~cm}^{3} /$ мин ( $\left.\left.\mathrm{sccm}\right)\right)$ проходила через кварцевый реактор с внешним резистивным нагревателем. В реакторе в кварцевом тигле находился порошок МСМЧК массой 1 г, толщина слоя МСМЧК не превышала 1 мм. Давление в реакторе было равным 1 атм. В реакторе поддерживалась постоянная температура $450^{\circ} \mathrm{C}$. Продолжительность синтеза составила 20 ч.

Для удаления $\mathrm{SiO}_{2}$ частицы MCMЧК/Si помещались в $0.015 \mathrm{M}$ водный раствор плавиковой кислоты. Продолжительность травления составляла 10 ч. Полученные частицы $n p$-Si многократно редиспергировались в деионизованной воде (10 МОм) под действием ультразвука, затем осаждались центрифугированием. Выход конечного продукта составил 0.6 г частиц $n p-\mathrm{Si}$ на 1 г МСМЧК.

Исследования морфологии частиц $n p-\mathrm{Si}$ выполнены на просвечивающем электронном микроскопе (ПЭМ) Jeol JEM-2100F. Для приготовления образца для ПЭМ-исследований частицы наносились на поддерживающую пленку из ультратонкой графеновой бумаги. Адсорбционно-структурные исследования проведены на анализаторе ASAP 2020 фирмы „Micromeritics“ при температуре $77 \mathrm{~K}$ с применением азота в качестве адсорбата. Значение удельной поверхности частиц $n p-\mathrm{Si}$ выполнено методом Брунауэра-Эммета-Теллера (БЭТ), распределение пор по размерам рассчитано с использованием нелокальной теории функционала плотности (НТФП), как описано ранее в работах $[17,25,26]$. Объем пор вычислялся из изотерм адсорбции при относительном давлении $P / P_{0}=0.994$. Распределение частиц $n p-\mathrm{Si}$ по размерам регистрировалось методом динамического светорассеяния (ДСР) на приборе Malvern Zetasizer Nano при температуре $25^{\circ} \mathrm{C}$.

Рамановские спектры и спектры фотолюминесценции (ФЛ) измерялись на спектрометре Horiba Jobin Yvon
T64000 с использованием в качестве источника излучения второй гармоники $\mathrm{Nd}$ : YAG-лазера $(\lambda=532 \mathrm{Hм})$. Спектрометр был оснащен конфокальным микроскопом, что позволяло фокусировать лазерный луч в пятно размером $\sim 1.5$ мкм. Плотность возбуждения $P_{\text {exс на по- }}$ верхности образца при измерении рамановских спектров и спектров ФЛ не превышала $1 \mathrm{\kappa BT} / \mathrm{cm}^{2}$. Калибровка спектрометра проводилась по лазерной линии и по линии тестового образца $\mathrm{Si}(111)$.

\section{3. Результаты и обсуждение}

Использование метода термического разложения моносилана в мезопорах частиц темплата позволило равномерно заполнить МСМЧК кремнием. Реализация равномерного заполнения стала возможна также благодаря особенностям внутренней структуры мезопористых частиц кремнезема. МСМЧК состоят из $\sim 10-15$ нм блоков плотноупакованных трубок $\mathrm{SiO}_{2}$ (внутренний диаметр $\sim 3$ нм, внешний $\sim 4$ нм), причем блоки разориентированы друг относительно друга $[17,25,26]$. Между блоками имеются мезопоры размером 3-7 нм [17,18,25], которые выполняют роль транспортных пор. Благодаря небольшой длине трубок $\mathrm{SiO}_{2}(10-15$ нм $)$ и наличию транспортных пор между блоками обеспечивается эффективный доступ $\mathrm{SiH}_{4}$ в мезопоры МСМЧК и удаление газообразных продуктов разложения.

В отличие от процесса заполнения макропор искусственных опалов кремнием [27-29], в котором был реализован конвективный массоперенос газовой смеси через поры темплата, в порах МСМЧК имеет место диффузия $\mathrm{SiH}_{4}$ внутрь частиц вследствие градиента концентрации (парциального давления) силана, обусловленного адсорбционными свойствами поверхности мезопор. По-видимому, $\mathrm{SiH}_{4}$ в первую очередь адсорбируется внутренней поверхностью трубок $\mathrm{SiO}_{2}$, где и начинает разлагаться, образуя $\mathrm{Si}$. Затем разложение $\mathrm{SiH}_{4}$ проходит на поверхности блоков $\mathrm{SiO}_{2} / \mathrm{Si}$ с образованием кремния в пространстве между блоками. Формируется прочный разветвленный „каркас“ из $\mathrm{Si}$, и вследствие этого после заполнения МСМЧК кремнием и последующего вытравливания $\mathrm{SiO}_{2}$ водным раствором $\mathrm{HF}$ удается получить сферические частицы $\mathrm{Si}$ той же формы и размера, что и исходные частицы мезопористого кремнезема. Таким образом, благодаря монодисперсности частиц темплата удалось синтезировать монодисперсные частицы нанопористого кремния (рис. 1). По данным ДСР, диаметр частиц $n p$-Si составил $425 \pm 40$ нм.

Микроскопические исследования подтверждают реализацию равномерного заполнения пор МСМЧК и получение монодисперсных сферических частиц пористого кремния после вытравливания темплата (рис. 1,2). На ПЭМ-изображениях высокого разрешения (ВРПЭМ) наблюдается ярко выраженная пористая структура (рис. $2, b)$. Отметим, что разбавленный раствор $\mathrm{HF}$ $(0.015 \mathrm{M})$ позволяет селективно вытравить $\mathrm{SiO}_{2}$ из ком- 


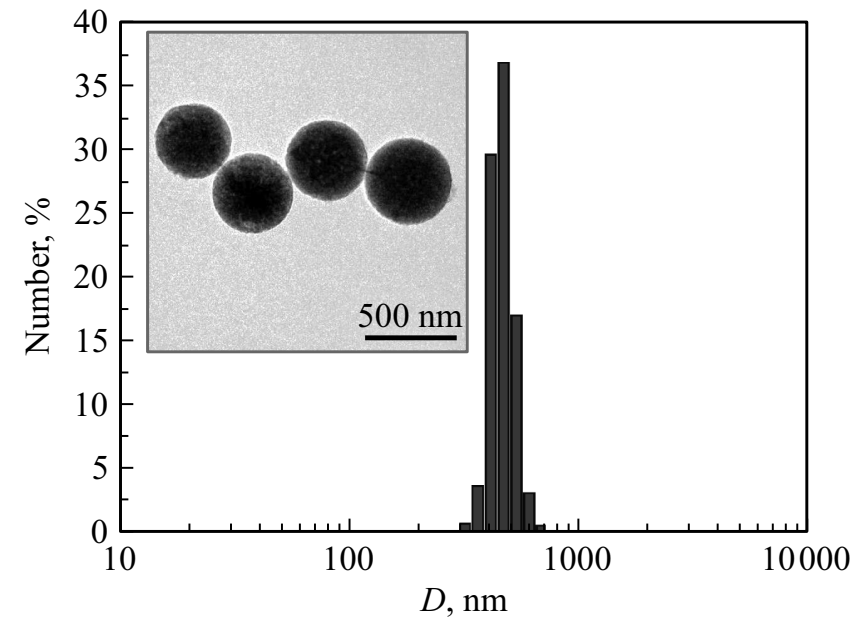

Рис. 1. Распределение диаметров частиц $n p-\mathrm{Si}$, измеренное методом ДСР. На вставке показано ПЭМ-изображение группы частиц.

позитных частиц $\mathrm{SiO}_{2} / \mathrm{Si}$, не растворяя $\mathrm{Si}$, поскольку для травления последнего требуется окислитель, например, $\mathrm{HNO}_{3}$.

На рис. 3 приведены результаты адсорбционноструктурного анализа кремниевых частиц. На изотерме адсорбции наблюдается широкий гистерезис в области относительных давлений $P / P_{o}=0.5-1$, свидетельствующий о наличии крупных мезопор, которые видны на увеличенном ПЭМ-изображении (рис. 2, $b$ ). Частицы обладают удельной поверхностью $255 \mathrm{M}^{2} / \Gamma$ и объемом пор $0.54 \mathrm{~cm}^{3} / \Gamma$. Высокие значения удельной поверхности и объема пор позволяют, в перспективе, использовать полученные частицы $n p-\mathrm{Si}$ в качестве наноконтейнера для токсичных химиопрепаратов в системах адресной доставки лекарств [1,3,9-11].
На рис. 3 (см. вставку) приведено распределение пор по размерам. Наблюдается отчетливый максимум распределения микропор при 1.4 нм. Кроме того, в образце имеются мезопоры размерами от 3 до $\sim 50 \mathrm{Hм}$ с максимумом распределения в области $16 \mathrm{HM}$, что приблизительно равно размеру блоков плотноупакованных трубок $\mathrm{SiO}_{2}$ в исходных МСМЧК. Такое изменение обусловлено, по-видимому, особенностями разложения $\mathrm{SiH}_{4}$ и формирования $\mathrm{Si}$ внутри МСМЧК. По-видимому, при температуре $450^{\circ} \mathrm{C}$ образование $\mathrm{Si}$, вследствие терморазложения $\mathrm{SiH}_{4}$, происходит преимущественно вблизи торцов трубок $\mathrm{SiO}_{2}$. Силан разлагается, успев проникнуть внутрь МСМЧК по транспортным порам, но не успевая продиффундировать в глубь трубок. Торцы цилиндрических мезопор МСМЧК закупориваются, препятствуя дальнейшему заполнению трубок $\mathrm{SiO}_{2}$ кремнием. В результате слой Si формируется преимущественно на внешней поверхности блоков плотноупакованных трубок $\mathrm{SiO}_{2}$. Однако, благодаря заполнению транспортных мезопор между разориентированными друг относительно друга блоками $[17,18,25]$, происходит образование прочного „каркаса“ из Si по всему объему МСМЧК и поэтому после вытравливания $\mathrm{SiO}_{2}$ частицы $n p-\mathrm{Si}$ не распадаются на фрагменты.

На рис. 4, кривая 1 представлен рамановский спектр синтезированных частиц $n p$-Si. Видно, что в спектре наблюдаются широкие полосы, характерные для аморфного $\mathrm{Si}$, соответствующие четырем раман-активным фононным модам: ТО (положение максимума при $475 \mathrm{~cm}^{-1}$ ), LO $\left(380 \mathrm{~cm}^{-1}\right)$, LA $\left(310 \mathrm{~cm}^{-1}\right)$, TA $\left(150 \mathrm{~cm}^{-1}\right)$ [30]. В спектре частиц также присутствует полоса (отмечена стрелкой), соответствующая ТО фононной моде нанокристаллического Si [31-34]. Исходя из данных рамановской спектроскопии можно утверждать, что $\mathrm{Si}$, образующий частицы $n p-\mathrm{Si}$, является аморфно-нанокристаллическим. С целью увеличения объемной доли
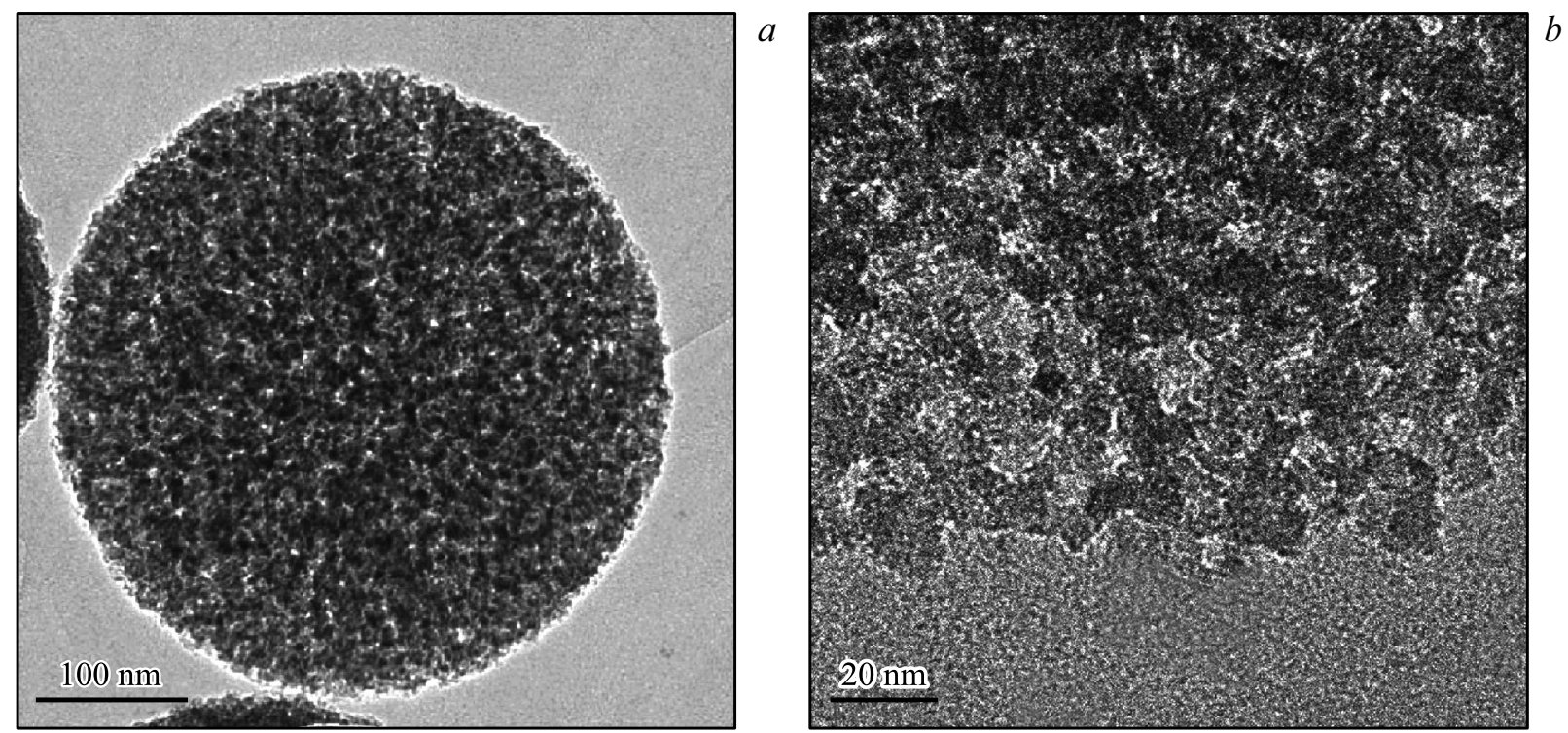

Рис. 2. ПЭМ $(a)$ и ВРПЭМ $(b)$ изображения частицы $n p$-Si. 
нанокристаллического $\mathrm{Si}$ проводился лазерный отжиг с мощностью $P_{\text {exc }}=5-20$ кВт/см ${ }^{2}$ продолжительностью 1 мин. Видно, что по мере увеличения интенсивности лазерного излучения в спектре частиц $n p$-Si возгорается узкая полоса (рис. 4). Максимум данной полосы, соответствующей $\mathrm{TO}$ моде $\mathrm{Si}$, смещается в высокочастотную область спектра с $491 \mathrm{~cm}^{-1}$ (кривая 1) до $519 \mathrm{~cm}^{-1}$ (кривая 4), что свидетельствует об увеличении размеров кристаллитов $\mathrm{Si}$ [35-38].

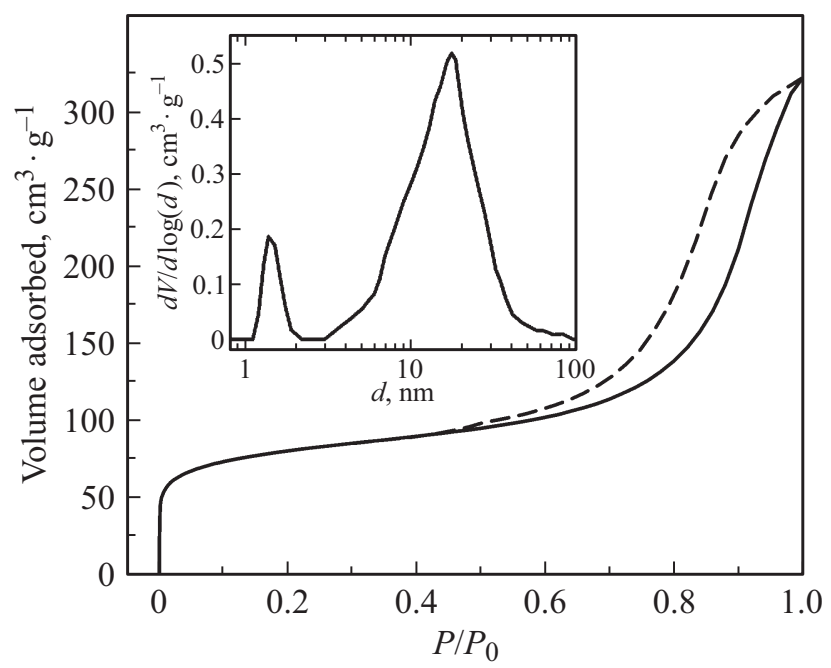

Рис. 3. Изотерма адсорбции азота на частицах $n p-\mathrm{Si}$ при 77 K. На вставке приведено распределение размеров пор, рассчитанное методом НТФП.

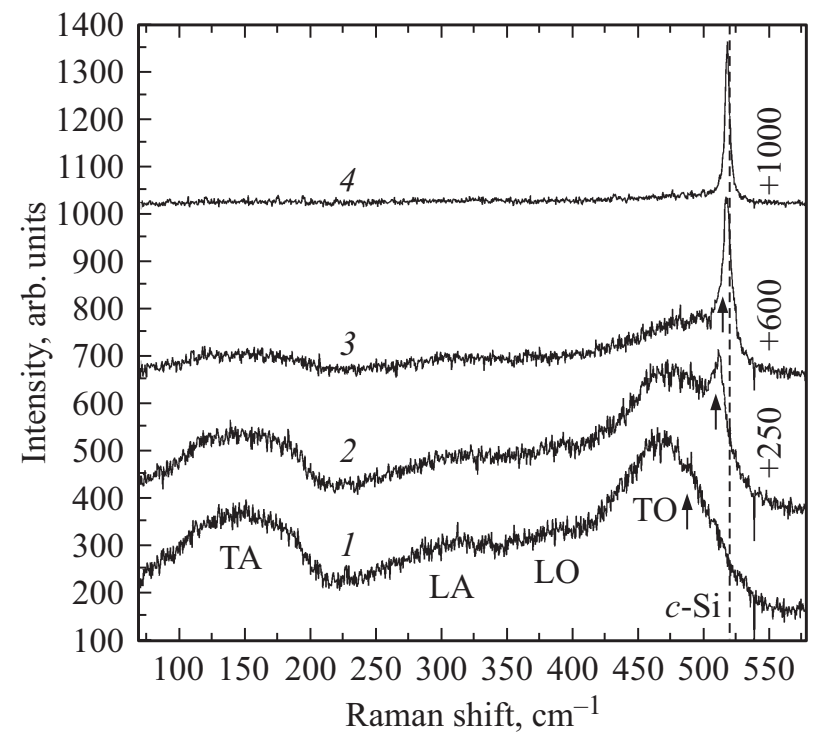

Рис. 4. Рамановские спектры частиц $n p-\mathrm{Si}$. $\lambda_{\text {exc }}=532$ нм, $P_{\text {exc }}=1 \kappa \mathrm{KT} / \mathrm{cm}^{2}, T=300 \mathrm{~K}$. Мощности лазерного отжига длительностью 1 мин, которому подвергались частицы перед регистрацией спектров: $1-0,2-5,3-10,4-20$ кВт/см². На рисунке обозначены раман-активные фононные моды кремния. Стрелками отмечены ТО фононные моды нанокристаллического Si в спектрах. Пунктирной линией показано положение ТО моды кристаллического кремния.

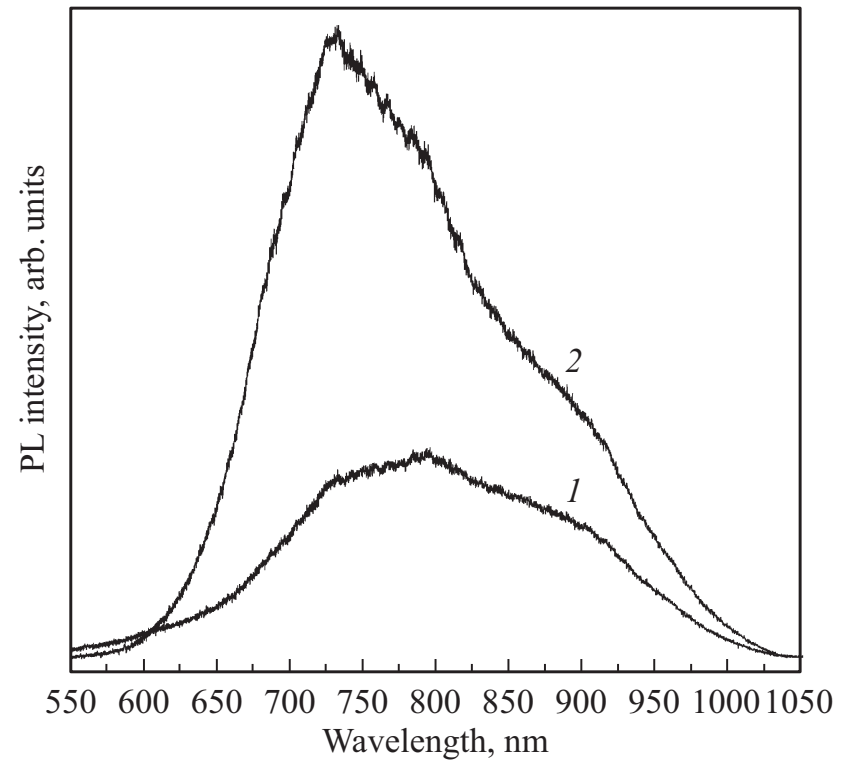

Рис. 5. Спектры ФЛ частиц $n p$-Si. $\lambda_{\text {ехс }}=532$ нм, $P_{\text {exc }}=0.1 \kappa \mathrm{KT} / \mathrm{cm}^{2}, T=300 \mathrm{~K}$. Мощности лазерного отжига длительностью 1 мин, которому подвергались частицы перед регистрацией спектров: $1-0,2-10 \kappa \mathrm{BT} / \mathrm{cm}^{2}$.

В спектре фотолюминесценции частиц $n p-\mathrm{Si}$ присутствуют широкие полосы в видимом и ближнем ИК спектральных диапазонах (рис. 5), наблюдавшиеся ранее в спектрах ФЛ нанокристаллического $\mathrm{Si}$ [37,39-42]. После лазерного отжига мощностью $P_{\mathrm{exc}}=5-10 \mathrm{\kappa BT} / \mathrm{cm}^{2}$ в течение 1 мин интенсивность ФЛ возрастает в $2-3$ раза. Наличие ФЛ в спектральной области, соответствующей окну прозрачности биологических тканей [43], обусловливает возможность использования полученных частиц в качестве люминесцентного маркера для контроля локализации частиц $n p-\mathrm{Si}$ в организме.

\section{4. Заключение}

В настоящей работе синтезированы субмикронные нанопористые частицы кремния посредством термического разложения моносилана в мезопорах темплата (монодисперсных частиц аморфного кремнезема) и последующего жидкостного травления материала темплата. Разработанный технологический подход и особенности внутренней структуры темплатных частиц $a-\mathrm{SiO}_{2}$ позволили добиться сферичности и монодисперсности получаемых частиц нанопористого $\mathrm{Si}$, среднеквадратичное отклонение их диаметров не превышает $10 \%$. По данным адсорбционно-структурного анализа синтезированные частицы нанопористого $\mathrm{Si}$ обладают большими удельной поверхностью $250 \mathrm{~m}^{2} / \Gamma$ и объемом пор $0.5 \mathrm{~cm}^{3} /$ г. Размер пор варьируется от единиц до нескольких десятков нанометров. Продемонстрировано, что полученные частицы люминесцируют в видимом и ближнем ИК 
спектральных диапазонах. Отжиг частиц приводит к увеличению интенсивности фотолюминесценции.

Полученные частицы могут, в перспективе, использоваться в медицине в качестве биоразлагаемых наноконтейнеров для лекарственных препаратов, одновременно являющихся люминесцентными маркерами.

\section{Благодарности}

Исследования методом ПЭМ выполнены с использованием оборудования федерального ЦКП „Материаловедение и диагностика в передовых технологиях“.

\section{Финансирование работы}

Работа выполнена с использованием средств госбюджета по государственному заданию 0040-2019-0012.

\section{Конфликт интересов}

Авторы заявляют, что у них нет конфликта интересов.

\section{Список литературы}

[1] J.-H. Park, L. Gu, G. von Maltzahn, E. Ruoslahti, S.N. Bhatia, M.J. Sailor. Nature Materials, 8, 331 (2009).

[2] Q. Shabir, A. Pokale, A. Loni, D.R. Johnson, L.T. Canham, R. Fenollosa, M. Tymczenko, I. Rodríguez, F. Meseguer, A. Cros, A. Cantarero. Silicon, 3, 173 (2011).

[3] H.A. Santos. Porous silicon for biomedical applications (Elsevier Ltd, 2014).

[4] J.G. Croissant, Y. Fatieiev, N.M. Khashab. Adv. Mater., 29, 1604634 (2017).

[5] L. Canham. Properties of porous silicon (INSPEC/IEE, London, 1997).

[6] R. Anthony, U. Kortshagen. Phys. Rev. B, 80, 115407 (2009).

[7] R. Mazzaro, F. Romano, P. Ceroni. Phys. Chem. Chem. Phys., 19, 26507 (2017).

[8] B. Bruhn, B.J.M. Brenny, S. Dekker, I. Doğan, P. Schall, K. Dohnalová. Light: Sci. Applications, 6, e17007 (2017).

[9] E.J. Anglin, L. Cheng, W.R. Freeman, M.J. Sailor. Adv. Drug. Deliv. Rev., 60, 1266 (2008).

[10] J. Salonen, A.M. Kaukonen, J. Hirvonen, V.-P. Lehto. J. Pharmaceutical Sci., 97, 632 (2008).

[11] D.S. Kumar, D. Banji, B. Madhavi, V. Bodanapu, S. Dondapati, A.P. Sri. Int. J. Pharmacy Pharmaceutical Sci., 1, 8 (2009).

[12] R.J. Martìn-Palma, M. Manso-Silván, V. Torres-Costa. J. Nanophotonics, 4, 042502 (2010).

[13] H.A. Santos, E. Mäkilä, A.J. Airaksinen, L.M. Bimbo, J. Hirvonen. Nanomedicine, 9, 535 (2014).

[14] V. Stojanovic, F. Cunin, J.O. Durand, M. Garcia, M. GaryBobo. J. Mater. Chem. B, 4, 7050 (2016).

[15] Y. Geng, P. Dalhaimer, S. Cai, R. Tsai, M. Tewari, T. Minko, D.E. Discher. Nature Nanotechnology, 2, 249 (2007).

[16] S. Rahmani, J.-O. Durand, C. Charnay, L. Lichon, M. Férid, M. Garcia, M. Gary-Bobo. Solid State Sci., 68, 25 (2017).

[17] D.A. Kurdyukov, D.A. Eurov, D.A. Kirilenko, J.A. Kukushkina, V.V. Sokolov, M.A. Yagovkina, V.G. Golubev. Microporous Mesoporous Mater., 223, 225 (2016).
[18] D.A. Kurdyukov, D.A. Eurov, D.A. Kirilenko, V.V. Sokolov, V.G. Golubev. Microporous Mesoporous Mater., 258, 205 (2018).

[19] Д.А. Курдюков, Д.А. Еуров, Е.Ю. Стовпяга, С.А. Яковлев, Д.А. Кириленко, В.Г. Голубев. ФТТ, 56, 995 (2014).

[20] D.A. Eurov, D.A. Kurdyukov, D.A. Kirilenko, J.A. Kukushkina, A.V. Nashchekin, A.N. Smirnov, V.G. Golubev. J. Nanopart. Res., 17, 82 (2015).

[21] Е.Ю. Стовпяга, Д.А. Еуров, Д.А. Курдюков, А.Н. Смирнов, М.А. Яговкина, В.Ю. Григорьев, В.В. Романов, D.R. Yakovlev, В.Г. Голубев. ФТТ, 59, 1598 (2017).

[22] Е.Ю. Стовпяга, Д.А. Еуров, Д.А. Курдюков, А.Н. Смирнов, M.A. Яговкина, D.R. Yakovlev, В.Г. Голубев. ФТП, 52, 1000 (2018).

[23] Д.А. Курдюков, Д.А. Еуров, Е.Ю. Стовпяга, Д.А. Кириленко, С.В. Коняхин, А.В. Швидченко, В.Г. Голубев. ФТТ, 58, 2454 (2016).

[24] D.A. Kurdyukov, D.A. Eurov, M.K. Rabchinskii, A.V. Shvidchenko, M.V. Baidakova, D.A. Kirilenko, S.V. Koniakhin, V.V. Shnitov, V.V. Sokolov, P.N. Brunkov, A.T. Dideikin, Ye.M. Sgibnev, L.Yu. Mironov, D.A. Smirnov, A.Ya. Vul', V.G. Golubev. Nanoscale, 10, 13223 (2018).

[25] Е.Ю. Трофимова, Д.А. Курдюков, Ю.А. Кукушкина, М.А. Яговкина, В.Г. Голубев. Физика и химия стекла, $\mathbf{3 7}$, 38 (2011).

[26] E.Yu. Trofimova, D.A. Kurdyukov, S.A. Yakovlev, D.A. Kirilenko, Yu.A. Kukushkina, A.V. Nashchekin, A.A. Sitnikova, M.A. Yagovkina, V.G. Golubev. Nanotechnology, 24, 155601 (2013).

[27] В.Н. Богомолов, В.Г. Голубев, Н.Ф. Картенко, Д.А. Курдюков, А.Б. Певцов, А.В. Прокофьев, В.В. Ратников, Н.А. Феоктистов, Н.В. Шаренкова. Письма ЖТФ, 24, 90 (1998).

[28] N.A. Feoktistov, V.G. Golubev, J.L. Hutchison, D.A. Kurduykov, A.B. Pevtsov, V.V. Ratnikov, J. Sloan, L.M. Sorokin. Semicon. Sci. Technol., 16, 955 (2001).

[29] V.N. Bogomolov, N.A. Feoktistov, V.G. Golubev, J.L. Hutchison, D.A. Kurdyukov, A.B. Pevtsov, R. Schwarz, J. Sloan, L.M. Sorokin. J. Non-Cryst. Sol., 266/269, 1021 (2000).

[30] A.T. Voutsas, M.K. Hatalis, J. Boyce, A. Chiang. J. Appl. Phys., 78, 6999 (1995).

[31] G. Faraci, S. Gibilisco, P. Russo, A.R. Pennisi, G. Compagnini, S. Battiato, R. Puglisi, S. La Rosa. Eur. Phys. J. B, 46, 457 (2005).

[32] G. Faraci, S. Gibilisco, P. Russo, A.R. Pennisi, S. La Rosa. Phys. Rev. B, 73, 033307 (2006).

[33] S.K. Gupta, P.K. Jha. Solid State Commun., 149, 1989 (2009).

[34] X. Jia, Z. Lin, T. Zhang, B. Puthen-Veettil, T. Yang, K. Nomoto, J. Ding, G. Conibeer, I. Perez-Wurfl. RSC Adv., 7, 34244 (2017).

[35] A.B. Pevtsov, V.Yu. Davydov, N.A. Feoktistov, V.G. Karpov. Phys. Rev. B, 52, 955 (1995).

[36] В.Г. Голубев, В.Ю. Давыдов, А.В. Медведев, А.Б. Певцов, Н.А. Феоктистов. ФТТ, 39, 1348 (1997).

[37] V.Y. Timoshenko, K.A. Gonchar, I.V. Mirgorodskiy, N.E. Maslova, V.E. Nikulin, G.K. Mussabek, Y.T. Taurbaev, E.A. Svanbayev, T.I. Taurbaev. Nanoscale Res. Lett., 6, 349 (2011).

[38] İ. Doğan, M.C.M. van de Sanden. J. Appl. Phys., 114, 134310 (2013).

[39] Y. Kanzawa, T. Kageyama, S. Takeoka, M. Fujii, S. Hayashi, K. Yamamoto. Solid State Commun., 102, 533 (1997). 
[40] M. Baran, B. Bulakh, N. Korsunska, L. Khomenkova, J. Jedrzejewski. Eur. Phys. J. Appl. Phys., 27, 285 (2004).

[41] E. Tuğay, R. Turan. J. Nanosci. Nanotechnology, 16, 4052 (2016).

[42] Z. Remes, J. Stolchík, A. Purkrt, M. Ledinský, J. Kupčík. Ceramics-Silikáty, 61, 136 (2017).

[43] A.M. Smith, M.C. Mancini, S. Nie. Nature Nanotechnology, 4, 710 (2009).

Редактор Г.А. Оганесян

\section{Template synthesis of monodisperse spherical nanoporous silicon particles of submicron size}

D.A. Kurdyukov, N.A. Feoktistov, D.A. Kirilenko, A.N. Smirnov, V.Yu. Davydov, V.G. Golubev

loffe Institute,

194021 St. Petersburg, Russia

Abstract Monodisperse spherical nanoporous silicon ( $n p-\mathrm{Si}$ ) particles of submicron size were fabricated by use of mesoporous silica particles as a template. Silicon was synthesized by thermal decomposition of monosilane within the mesopores, and then the template material $\left(a-\mathrm{SiO}_{2}\right)$ was removed by wet etching technique. The particles obtained have narrow size scatter $(<10 \%)$, large specific surface area $\left(250 \mathrm{~m}^{2} \mathrm{~g}^{-1}\right)$ and pore volume $\left(0.5 \mathrm{~cm}^{3} \mathrm{~g}^{-1}\right)$. It was shown that $n p$-Si particles exhibit photoluminescence in Vis-NIR spectral range. 